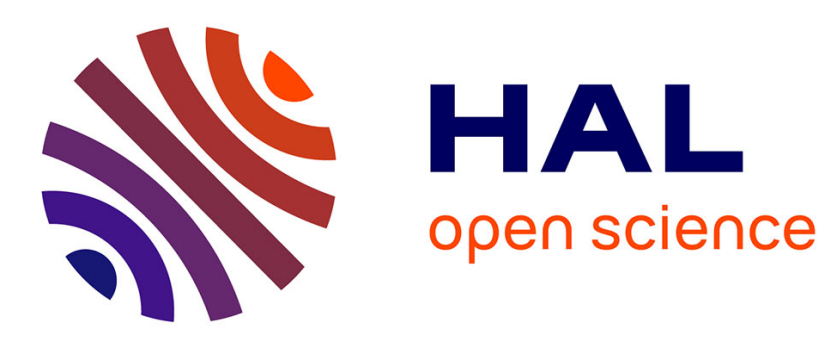

\title{
Design Methodology for a SEAREV Wave Energy Converter
}

Marie Ruellan, Hamid Ben Ahmed, Bernard Multon, Christophe Josset, Aurélien Babarit, Alain H. Clément

\section{- To cite this version:}

Marie Ruellan, Hamid Ben Ahmed, Bernard Multon, Christophe Josset, Aurélien Babarit, et al.. Design Methodology for a SEAREV Wave Energy Converter. Energy Conversion, 2010, 25 (3), pp.760767. hal-00528937

\section{HAL Id: hal-00528937 https://hal.science/hal-00528937}

Submitted on 22 Oct 2010

HAL is a multi-disciplinary open access archive for the deposit and dissemination of scientific research documents, whether they are published or not. The documents may come from teaching and research institutions in France or abroad, or from public or private research centers.
L'archive ouverte pluridisciplinaire HAL, est destinée au dépôt et à la diffusion de documents scientifiques de niveau recherche, publiés ou non, émanant des établissements d'enseignement et de recherche français ou étrangers, des laboratoires publics ou privés. 


\title{
Design Methodology for a SEAREV Wave Energy Converter
}

\author{
Marie Ruellan, Hamid BenAhmed, Bernard Multon, Christophe Josset, Aurelien Babarit, \\ and Alain Clement
}

\begin{abstract}
This article will begin by presenting two power take-off (PTO) technologies for the SEAREV wave energy converter (WEC) followed by the design methodology applied to electromagnetic generator cycles for the all-electric solution. The operating principle associated with the SEAREV WEC will be described before discussing the two conversion technologies intended to transform wave energy into electricity. The types of systems are twofold: hydroelectric and allelectric. The strong coupling between the hydrodynamic, mechanical and electrical phenomena heavily influences the behavior of the recovery (PTO) system and leads to a complex system design that requires a full-scale modeling description. A unique design methodology for the all-electric conversion chain has been developed around several distinct control modes, including one featuring power leveling.
\end{abstract}

Index Terms - wave energy conversion - electromagnetic generator - optimization - design methodology.

\section{INTRODUCTION}

According to the World Energy Council (WEC) [1], between 140 and $700 \mathrm{TWh} /$ year of wave energy are available and economically-accessible, i.e. approximately $1 \%$ to $5 \%$ of the annual worldwide demand for electricity. The recoverable energy could reach as high as 2,000 TWh/year with more efficient conversion systems. Swells are described as the overlapping of several gradual and monochromatic elementary waves, with all phases being random. Studies have shown that the sea state, i.e. the quantity of energy contained within each of the elementary waves making up a swell, is a slowly-varying non-periodic function. The sea state may be modeled, according to the hydrodynamic community, within the frequency space $f$ by means of an energy spectrum that depends upon two parameters, i.e.:

- the significant height (peak-to-valley) denoted $H_{s}$. This parameter corresponds to the average height of the highest third of the waves [2]; and

- the peak period of the waves $T_{p}=1 / \mathrm{f}_{p}$, where $\mathrm{f}_{p}$ corresponds to the highest peak in the frequency spectrum of the wave field (Fig. 1).

The figure 1 shows a temporal measurement of the wave elevation. The significant height is indicated. The energy spectrum is also presented and the peak frequency is indicated.

For an aleatory swell, equation 1 below yields an approximation for its energy potential (in $\mathrm{W} / \mathrm{m}$ ):

$$
P=\frac{\rho g^{2}}{32 \pi} H_{s}^{2} T_{p}
$$
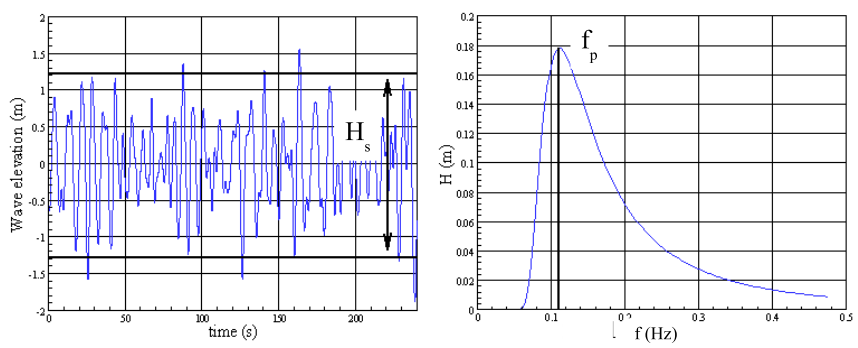

Fig. 1: Wave elevation measurement and wave energy spectrum

where $\rho$ is the mass density of water and $g$ the gravitational constant.

Table I provides an order of magnitude for the recoverable power $\mathrm{P}$ vs. swell height $H_{s}$ and peak period $T_{p}$.

\begin{tabular}{ccc}
$T_{p}(s)$ & $H_{s}(\mathrm{~m})$ & $\mathrm{P}(\mathrm{kW} / \mathrm{m})$ \\
\hline 6 & 1 & 2.4 \\
\hline 9 & 2.5 & 22.5 \\
\hline 12 & 6 & 173
\end{tabular}

TABLE I: Exemplary swell energy profiles

\section{Principle Behind the SEAREV System}

The WEC concept is based on a pendulum set in a closed buoy actuated by the swell through excitation forces [3] [4] (see Fig. 2). The lever or pendulum executes rotational movements transmitted to an active recovery system (in turn coupled to a charge via an electronic power converter), which recovers a portion of its kinetic energy produced. In order to obtain a PTO well suited to the swell characteristics associated with a particular geographic site, it is to be optimized by incorporating the actual measured swell cycles. Moreover, the design and optimization of such a system necessitate including the rather strong couplings physically existing between the hydrodynamic, mechanical and control phenomena. In an initial approach, the electromechanical part may be modeled by a simplified recovery function and confined to the recovery braking torque, whose evolution over time has been optimized in the aim of maximizing, for a given set of excitation conditions, electrical energy while minimizing the size of the conversion chain.

The computation of the electrical power output requires determining movements of the coupled device $\{$ buoy + pendulum + generator with control $\}$. Hence, a 


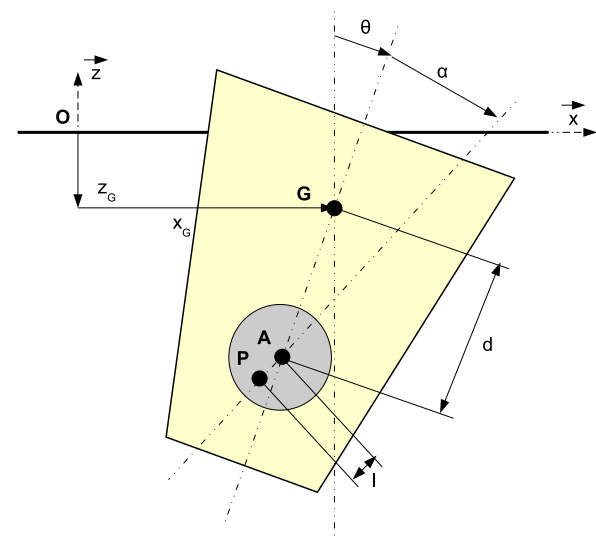

Fig. 2: Schematic diagram of the SEAREV pendular wave energy converter [4]

multi-physical hydrodynamic-mechanical-electrical modeling description must be derived. The movement is supposed to be plane.

The general equation to be solved is of the following form [3]:

$$
M . \overrightarrow{\ddot{X}}=\sum \overrightarrow{F_{\text {ext }}}
$$

where $\mathrm{M}$ represents the system's inertia matrix and $\vec{X}=[\mathrm{xG} z \mathrm{z} \theta \alpha]$ is the displacement vector (Fig. 2). $\overrightarrow{F_{e x t}}$ is the vector of generalized forces:

$$
\overrightarrow{F_{e x t}}=\overrightarrow{F_{p}}+\overrightarrow{F_{H}}+\overrightarrow{F_{R}}+\overrightarrow{F_{s}}+\overrightarrow{T_{R}}
$$

$F_{p}$ denotes the force being exerted by the pendulum; this force depends on $\mathrm{X}$, and on the set of geometric parameters for both the buoy and the pendulum.

$F_{H}$ stands for the hydrostatic force due to buoyancy.

$F_{R}$ is the so-called radiation force corresponding to the reaction of the $\{$ buoy + pendulum $\}$ system on the swell.

$T_{R}$ is the energy recovery torque.

Swell excitation forces $F_{s}$ are calculated from a set of imposed swell conditions for a given overall buoy geometry $[5]$.

In the case of our simplified system set-up, several simplifications have been made. Buoy movements are supposed to be small enough to linearise the equations. A monodirectional cylindric wave (in infinite depth) is considered and as a result just three swell force components on the buoy warrant attention: the horizontal force $F_{s X}$, the vertical force $F_{s Z}$, and the y-axis moment $F_{s \theta}$. At last, the fluid-structure interaction has been modelised as part of the linearized theory of potential flow [6].

The buoy shape and the data are presented on figure 3 and in table $\Pi$ respectively.

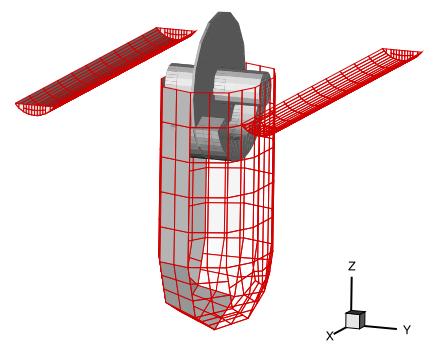

Fig. 3: 3D view of the SEAREV [4]

\begin{tabular}{cc} 
Buoy & \\
\hline Length & $20 \mathrm{~m}$ \\
Width & $16 \mathrm{~m}$ \\
Draft & $14,4 \mathrm{~m}$ \\
Mass (steel) & 277 tonnes \\
Watter mass & 8900 tonnes $\cdot \mathrm{m}^{2}$ \\
Inertia & 13000 tonnes $\cdot \mathrm{m}^{2}$ \\
& \\
Pendulum & $4.18 \mathrm{~m}$ \\
Radius & 272 tonnes \\
Mass & $2.29 \mathrm{~m}$ \\
Pendular length & 1700 tonnes $\cdot \mathrm{m}^{2}$ \\
Inertia
\end{tabular}

TABLE II: Dimensions of the SEAREV [4]

\section{ENERGY CONVERSION CHAIN}

In the following, the two technological solutions intended to convert mechanical energy from the pendulum excited by the swell into electrical energy, will be presented.

\section{A. The "hydroelectric" solution [7]}

In the specific case of wave energy converters, hydraulic conversion systems are often used given their suitability to wave energy applications, which display the following properties:

- Low speeds and high forces are induced by the waves. In industry, hydraulic systems are commonly used whenever higher forces and smaller motions are required;

- Power output fluctuates in both time and amplitude. Coupled with a pneumatic storage device, the PTO can smooth incident power fluctuations.

With the hydraulic solution, the SEAREV PTO is composed of five main elements. First, a mechanical gear is used in order to increase rotational speed while decreasing the input torque. A double-effect linear hydraulic ram, connecting the gear to the floating hull, then transforms the rotation into a high-pressure form; it pumps fluid from the low-pressure tank (atmospheric pressure - 1 bar) to the high pressure accumulator (250 bar), whose volume equals $1 \mathrm{~m}^{3}$. Energy is stored in this accumulator by means of gas compression. Once enough energy has been stored, the accumulator supplies pressurized fluid at a nominal 


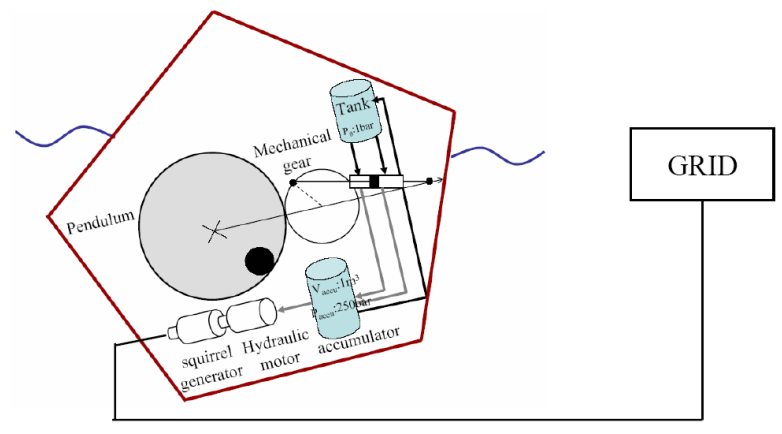

Fig. 4: Synopsis of the "hydroelectric" conversion chain

flow rate to a hydraulic motor coupled to an induction generator, which in turn is directly coupled to the grid. Electricity can then be generated and the fluid is released back into the tank at low pressure. A sample of the results obtained from this study appear in Table III below.

\begin{tabular}{llllll}
\hline & & $\begin{array}{l}\text { Viscous } \\
\text { damper }\end{array}$ & \multicolumn{3}{c}{ Hydraulic PTO } \\
\hline$T_{p}(s)$ & $H_{s}(\mathrm{~m})$ & $\begin{array}{l}E_{\text {extracted }} \\
(\mathrm{kWh})\end{array}$ & $\begin{array}{l}E_{\text {extracted }} \\
(\mathrm{kWh})\end{array}$ & $P_{0}(\mathrm{bar})$ & $\begin{array}{l}P_{\text {nominal }} \\
(\mathrm{kW})\end{array}$ \\
\hline 9 & 1 & 8 & 8 & 30 & 300 \\
\hline 9 & 3 & 62 & 82 & 150 & 300 \\
\hline 9 & 5 & 130 & 155 & 190 & 340 \\
\hline
\end{tabular}

TABLE III: Results using hydraulic PTO

\section{B. The All-electric solution}

An all-electric solution has also been assessed for potential industrial application following an initial electrohydraulic phase (see Section III-A). The remainder of this article will lay out the design methodology for this solution. The pendulum is damped by an electromagnetic generator driven by an IGBT static converter using pulse width modulation (2 three-phase bridges, back-to-back on both the machine and network sides), in association with a system that imposes a set of optimized control laws. The generator may be directly coupled to the pendulum (i.e. direct drive) or coupled via a mechanical multiplier (both of these options are currently under study). The research presented herein concerns the optimal electromagnetic generator design and its static converter solely in the direct drive mode. The multi-physical couplings and the swell cycle complexity necessitate developing a specific design optimization methodology that incorporates the control laws.

\section{Design methodology for the All-electric SOLUTION}

\section{A. A heavily-coupled multi-physical problem}

This section will address the design methodology employed for the electro-magneto-mechanical solution. The system is submitted to fluctuating swells that have previously been characterized. In order to recover the maximum

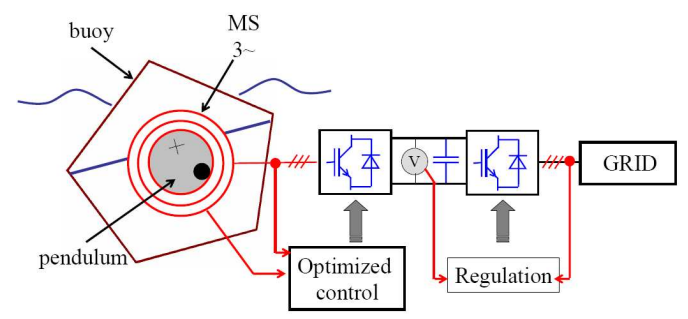

Fig. 5: Synopsis of the electro-magneto-mechanical conversion chain for the all-electric solution

amount of energy, certain elements need to be optimized, namely the hydrodynamic shape of the system, the electromagnetic generator and the control strategy. The coupling between system elements is strong. The buoy has been optimized by the fluid mechanics research team at the Ecole Centrale engineering school in Nantes (western France) [8], while optimization of the electric generator was performed by the SATIE laboratory team working at the ENS de Cachan educational facility. This generator will basically be handled like a device capable of imposing a braking torque $T_{R}(t)$. Following optimization, it appears that a viscous friction type of torque shape is indeed well adapted:

$$
T_{R}(t)=\beta \dot{\theta}(t)
$$

The reaction of this braking torque first on the pendulum, then on both the buoy and the swell, has well been taken into account by the general model.

Based on these excitation forces and in accordance with a multi-physical hydrodynamic-mechanical-electrical model, the power and the electrical energy output are calculated at each point in time over a fixed period $\Delta \mathrm{T}$. Given the coupling indicated above, the choice of the control mode exerts a significant influence on overall system behavior as well as on generator design. The optimization step consists of seeking the law of instantaneous electromagnetic torque variation $T_{R}(t)$ that maximizes energy output and minimizes peak power. The diagram below illustrates this optimization methodology.

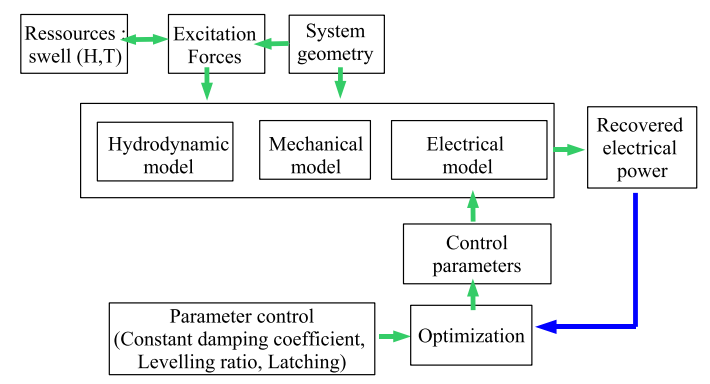

Fig. 6: Synopsis of the swell generator design 


\section{B. Control modes}

Three distinct control methods have been examined [9]:

- optimization of the viscous damping coefficient $\beta$,

- power leveling, and

- latching-based control [6] [10].

\section{1) Optimization with constant damping coefficient $\beta$}

Firstly a viscous damping type of torque is imposed: $T_{R}(t)=\beta \dot{\theta}(t)$.

where $\beta$ is the viscous damping coefficient, which remains constant over the full cycle (including the startup phase with the transient pendular motion ), and which must be optimized. The optimization problem consists in seeking the values of $\beta$ such that the mechanical energy output $W_{e}$ is maximized. Figure 7 presents the mechanical energy output according to the viscous damping for two wave cycle simulations.

$$
E_{e}=\int \beta \theta(\dot{t})^{2} d t
$$

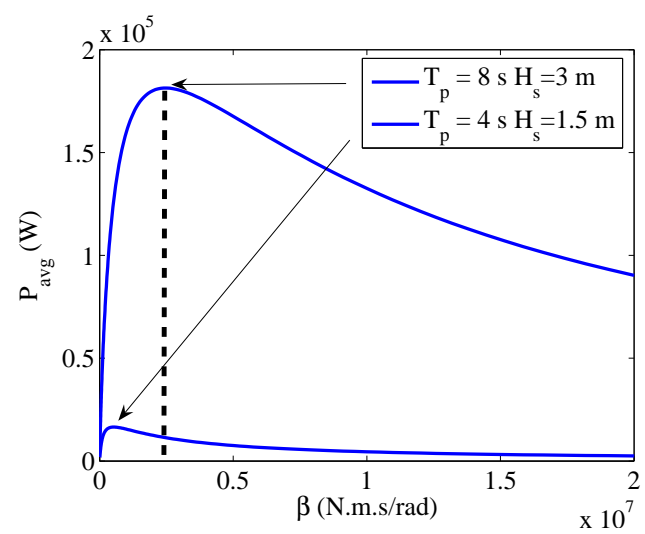

Fig. 7: Average power vs. damping coefficient $\beta$

Simulations must be run over period cycles $\Delta T>>T_{p}$ long enough to reach the mechanically-settled operating range. A sensitivity study of simulation time with respect to the average power calculation has been conducted. A minimum simulation time thus proves necessary before the transient state can be neglected. We set a simulation time of $800 \mathrm{sec}$ for the purpose of our simulation runs (see Fig. 8).

Figure 9 displays the fluctuations in power output over a $800 \mathrm{sec}$ cycle for a swell with a characteristic height of $3 \mathrm{~m}$ and period of $8 \mathrm{sec}$; this swell will constitute our reference for the remainder of the discussion. The graph shows the very strong variations in instantaneous power, which turn out to be highly disadvantageous in terms of both system cost and quality of energy produced.

Simulations were also run on various types of swells. The plots of speed vs power (Fig. 10) and speed vs torque (Fig. 11) have been traced for four types of swells.

The optimal value of damping coefficient $\beta_{\text {opt }}$ depends on the type of swell acting upon the system and must

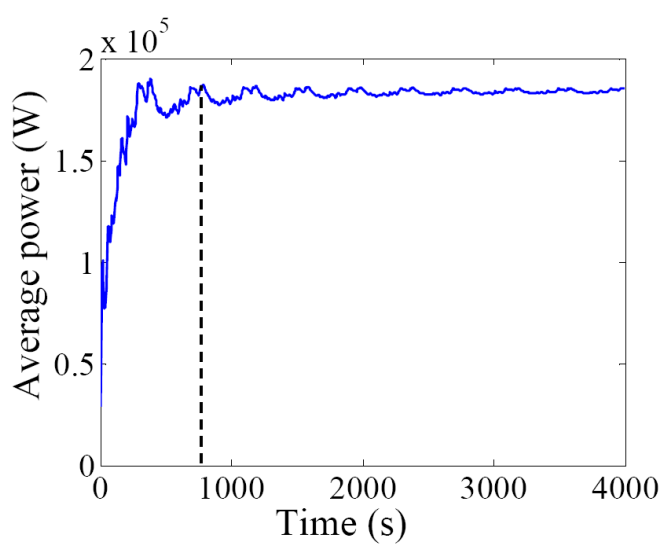

Fig. 8: Average power vs. simulation time

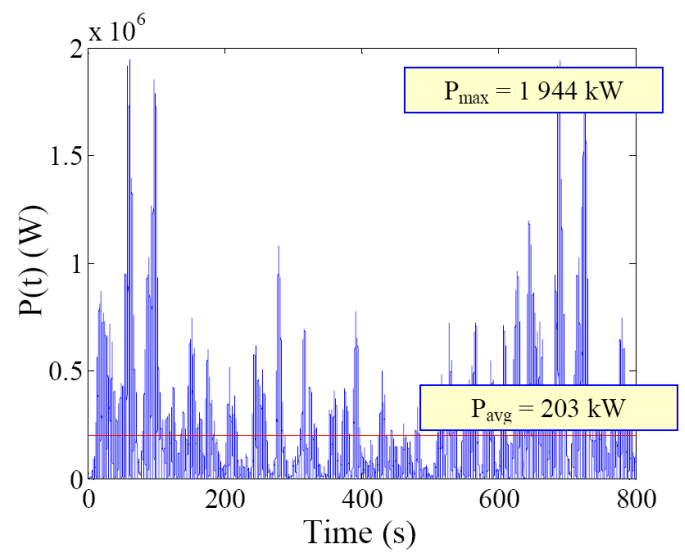

Fig. 9: Power output with constant $\beta_{\text {opt }}$ over the entire cycle

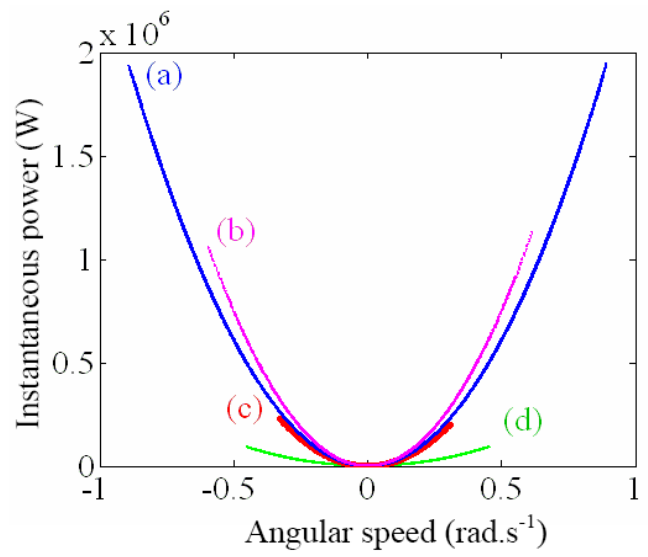

Fig. 10: Point cloud of the instantaneous power vs. angular speed for several swells - (a) $\mathrm{Tp}=8 \mathrm{~s}, \mathrm{Hs}=3 \mathrm{~m}$; (b) $\mathrm{Tp}=$ $10 \mathrm{~s}, \mathrm{Hs}=3 \mathrm{~m} ;$ (c) $\mathrm{Tp}=5 \mathrm{~s}, \mathrm{Hs}=1 \mathrm{~m} ;$ (d) $\mathrm{Tp}=5 \mathrm{~s}, \mathrm{Hs}=$ $2 \mathrm{~m}$

be adjusted for swell characteristics. The average power output levels (Fig. 12) along with the corresponding optimal values of recovery coefficient $\beta_{\text {opt }}$ (Fig. 13) will be presented, in the form of a scatter diagram, for various 


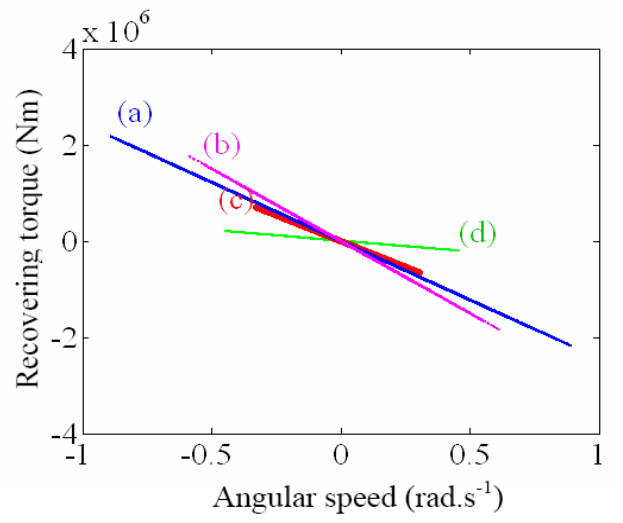

Fig. 11: Point cloud of the instantaneous torque vs. angular speed for several swells - (a) $\mathrm{Tp}=8 \mathrm{~s}, \mathrm{Hs}=3 \mathrm{~m}$; (b) $\mathrm{Tp}=$ $10 \mathrm{~s}, \mathrm{Hs}=3 \mathrm{~m} ;$ (c) $\mathrm{Tp}=5 \mathrm{~s}, \mathrm{Hs}=1 \mathrm{~m} ;$ (d) $\mathrm{Tp}=5 \mathrm{~s}, \mathrm{Hs}=$ $2 \mathrm{~m}$

types of swells.

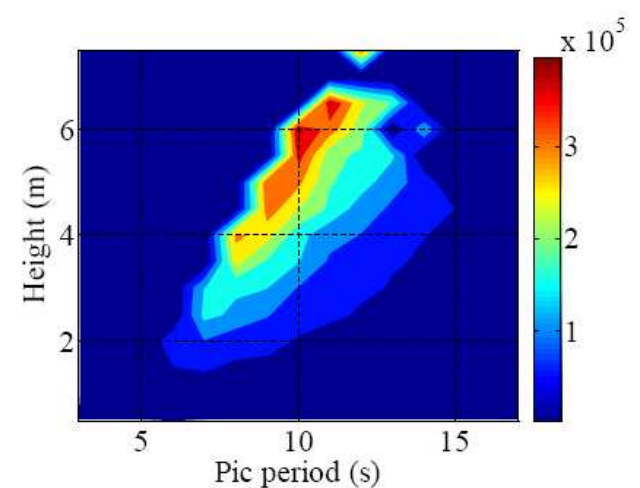

Fig. 12: Scatter diagram of average power output (W) with constant $\beta_{\text {opt }}$ over a cycle with constant characteristics

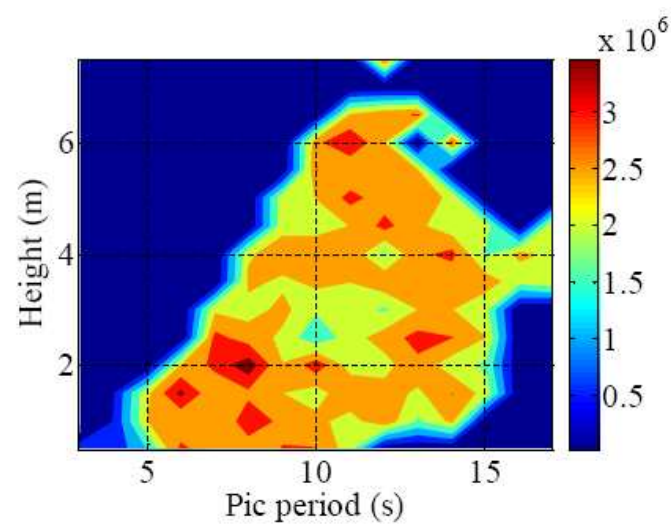

Fig. 13: Scatter diagram of optimal recovery damping coefficient $(\mathrm{Nms} / \mathrm{rad})$ with constant $\beta_{\text {opt }}$ over a cycle with constant characteristics

\section{2) Power Levelling}

The sizable fluctuations in power output cause the electric conversion system to be oversized. A leveling of the converted power would therefore serve to better optimize the economic return. This leveling is obtained in the present case by means of modifying (reducing) the value of the recovery damping coefficient $\beta$. For those phases in which the power lies below the imposed leveling power, the value of $\beta$ is held at an optimized constant, in order to maximize average power over the entire cycle. For those phases in which the power generated is greater than the leveling power, the coefficient $\beta$ varies temporally such that the power generated remains constant and equal to the leveling power (i.e. generator operating at constant power).

The leveling power is defined as ( $\alpha$ is the leveling ratio):

$$
P_{l e v}=\alpha \mathrm{P}_{\max \text { before leveling }}
$$

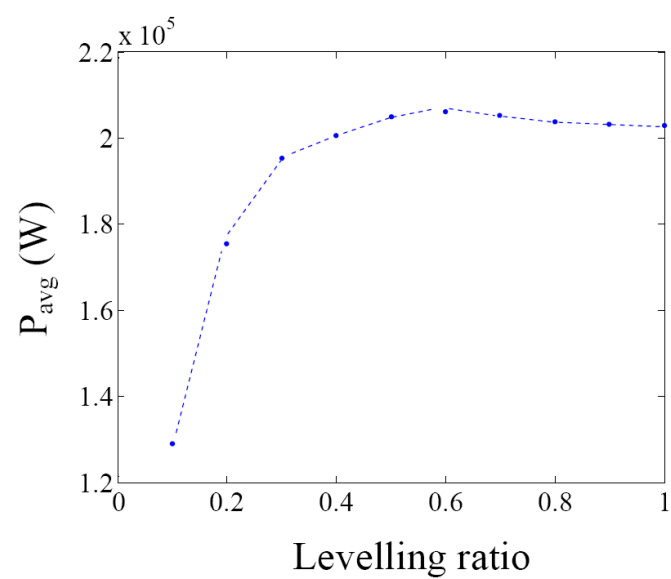

Fig. 14: Power output vs. leveling power $\alpha$

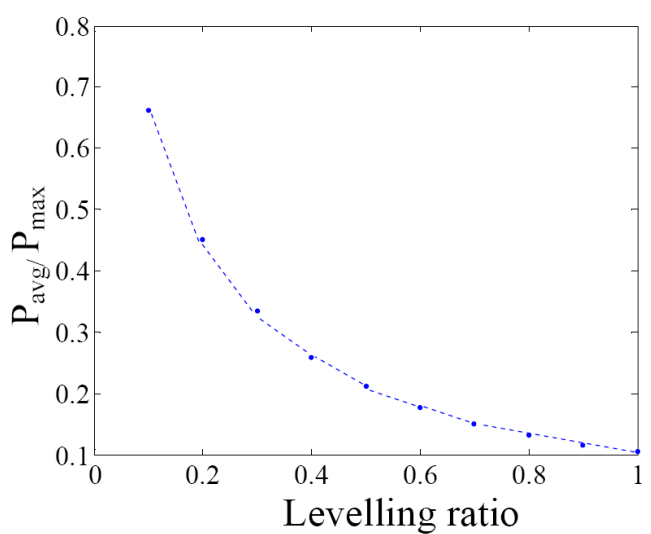

Fig. 15: Average power-to-maximum power ratio vs. leveling power $\alpha$

Such a control has enabled recovering a certain amount of average power (see Fig. 14) while limiting the average power-to-peak power ratio (see Fig. 15). This power recovery is indeed characteristic of the power electronics design. The generator is not directly related to the peak power and undergoes a separate optimization procedure. We show (fig. 16. 17) in both the Speed, Power planes 
and Speed, Torque planes the set of points swept during a single swell cycle and for various leveling ratios on the reference swell.

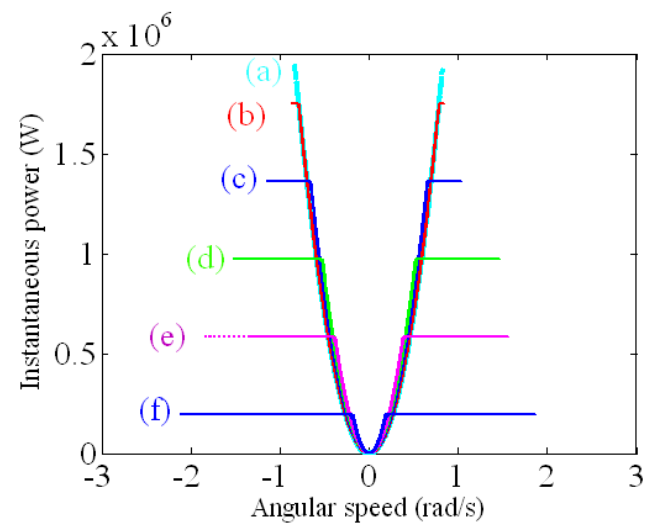

Fig. 16: Point cloud of the instantaneous power vs. angular speed for several power leveling ratios - (a: $\alpha=1)$, (b: $\alpha$ $=0.9),(\mathrm{c}: \alpha=0.7),(\mathrm{d}: \alpha=0.5),(\mathrm{e}: \alpha=0.3),(\mathrm{f}: \alpha=0.1)$

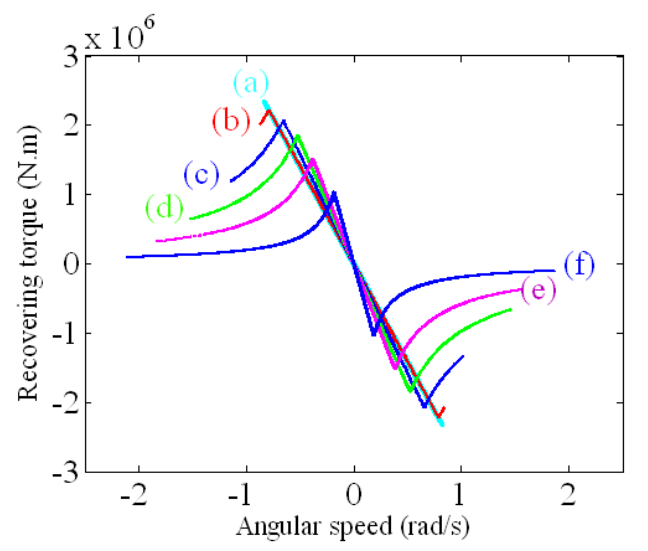

Fig. 17: Point cloud of the instantaneous torque vs. angular speed for several power leveling ratios - (a: $\alpha=1)$, (b: $\alpha$ $=0.9),(\mathrm{c}: \alpha=0.7),(\mathrm{d}: \alpha=0.5),(\mathrm{e}: \alpha=0.3),(\mathrm{f}: \alpha=0.1)$

Figure 18 depicts an instantaneous recording of the power for a leveling ratio of $30 \%$, obtained for the reference swell.

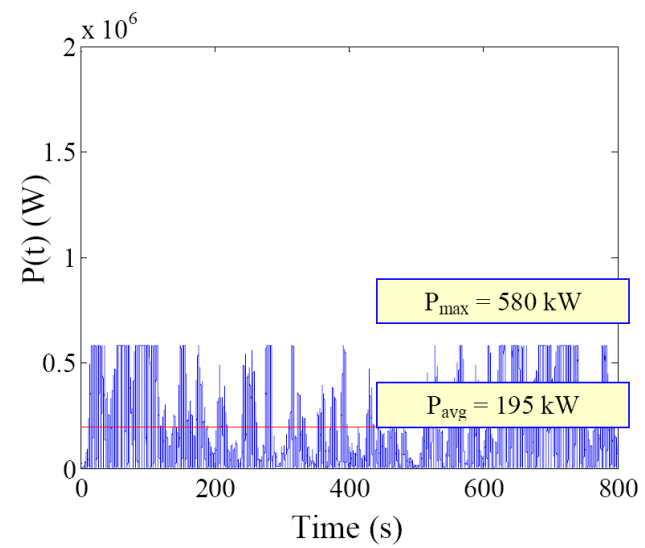

Fig. 18: Power output after power leveling (30\% ratio)

\section{3) Latching}

Latching control consists of locking (latching) the motion of the body at the instant when its velocity vanishes, while waiting for the wave force to have reached the optimal phase to release the body. The body then starts moving from this initial position to the next vanishing velocity position, where it is once again latched, and so forth and so on. Instead of being a smooth, continuous function, the body position is a succession of transient motion ramps separated by resting stages. Action upon the system is therefore binary: either the body is latched, or it is free to move illustred by figure 19 and equation 6 .

$$
E_{e}=\int \beta \dot{\theta}(t)^{2}(1-u(t)) d t
$$

With

$$
u(t)= \begin{cases}1 & \text { as we stop the pendulum at } \dot{\theta}=0 \\ 0 & \text { as the pendulum is free to move }\end{cases}
$$

The instant of latching is imposed by the dynamics of the body itself (i.e. vanishing velocity); thus, the control variable is simply the duration of the latching phase $t$, or equivalently the instant of release. This mode of control, applied to the heave motion of the buoy, was proposed by Budal and Falnes [6]. It allows to increase the pendulum position and velocity amplitude and thus, to increase the average power output. Figure 20 provides an example of results obtained under the same conditions as for the two other strategies with latching control. 

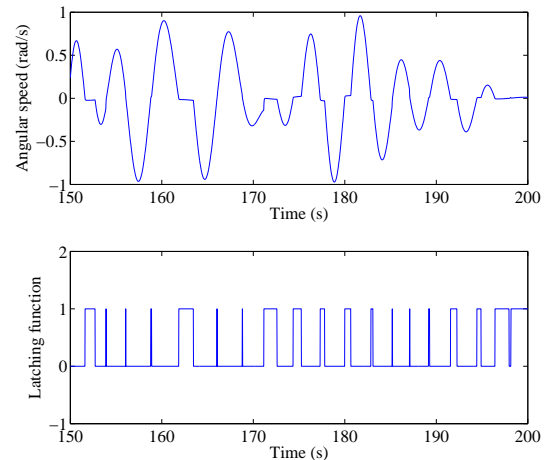

Fig. 19: Zoom on the angular speed and latching function

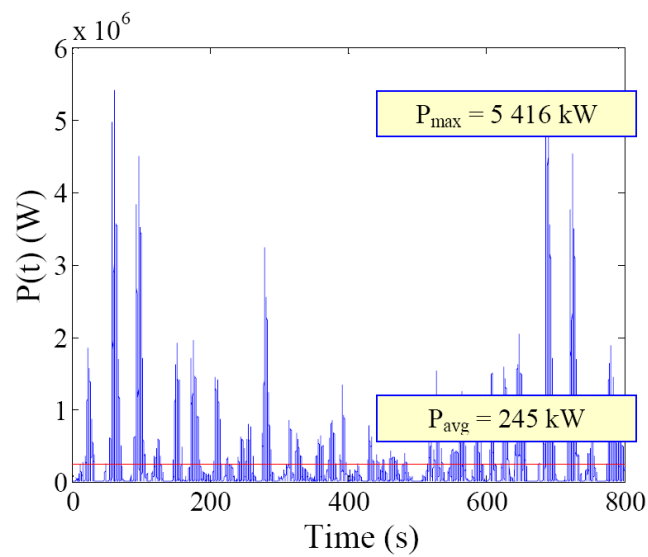

Fig. 20: Power output with latching control

\section{Electromagnetic generator}

We have sought to perform a preliminary design of the electromagnetic generator on the basis of results obtained from a given swell cycle (i.e. our reference cycle) and with the various types of control already presented. This design study is conducted on a classical synchronous machine structure featuring surface magnets and a radial field. The study does not allow determining the optimal machine, yet has yielded an applicable methodology [11] [12] [13].

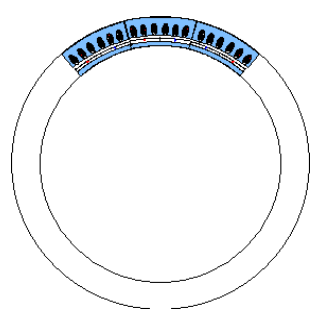

Fig. 21: Generator architecture - A synchronous machine with radial flux and mounted surface magnets (only 3 pole pairs shown)

The table IV presents the power output, peak power, RMS torque, maximum torque and maximum speed for the three control modes.

\begin{tabular}{lccc} 
& constant $\beta_{\text {opt }}$ & Power leveling & latching \\
\hline$<\mathrm{P}>$ opt $(\mathrm{kW})$ & 203 & 195 & 245 \\
$\widehat{P}_{\text {opt }}(\mathrm{kW})$ & 1944 & 583 & 5416 \\
$\left\langle P>_{\text {opt }}\right.$ & 0,10 & 0,34 & 0,05 \\
$\widehat{P_{\text {opt }}}$ & 0,8 & 1,8 & 1,4 \\
Max. speed $(\mathrm{rad} / \mathrm{s})$ & 756 & 775 & 830 \\
Max. torque $(\mathrm{kN} . \mathrm{m})$ & 2341 & 1524 & 3907 \\
$\mathrm{RMS}$ torque $(\mathrm{kN} . \mathrm{m})$ &
\end{tabular}

TABLE IV: Results table for the three control modes

The goal herein is to determine the set of optimal geometric characteristics for the synchronous generator that enable minimizing, from a Pareto perspective, two conflicting objectives: total losses, and the mass of active parts. This search is carried out by focusing on the torque $T_{R}(t)$ and rotational speed obtained during the previous system optimization steps over a given operating cycle. In what follows, we will focus solely on the directdrive solution. Total mass constitutes one criterion among others, as the cost of raw materials could be used similarly in weighting materials by their specific cost instead of their mass density. The design outcome for a swell with a characteristic height of $3 \mathrm{~m}$ and period of $8 \mathrm{sec}$ (i.e. the reference swell) is shown in Figure 22. Depending on the site where the swell generator is located, these characteristics might not necessarily be the most severe, but merely serve as an example. As we can see, the objectives are actually contradictory. The maximum total losses are get with the latching control and are equal to $15.4 \mathrm{~kW}$. At last the three Pareto front are very closed.

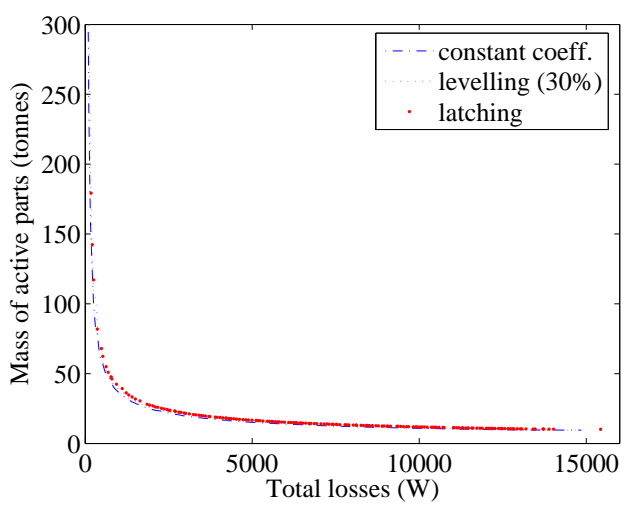

Fig. 22: Optimization of the three control modes in direct drive

The dimensions of machines with the same 4-kW losses can now be compared for the all three control modes [9].

It should be remarked that the generator design for this particular swell is only minimally affected by the choice of control mode (as we could already suppose with the Pareto front). Latching proves to be slightly less favorable. The discrepancy is especially noteworthy on peak power and thus on the cost associated with the static converter. 


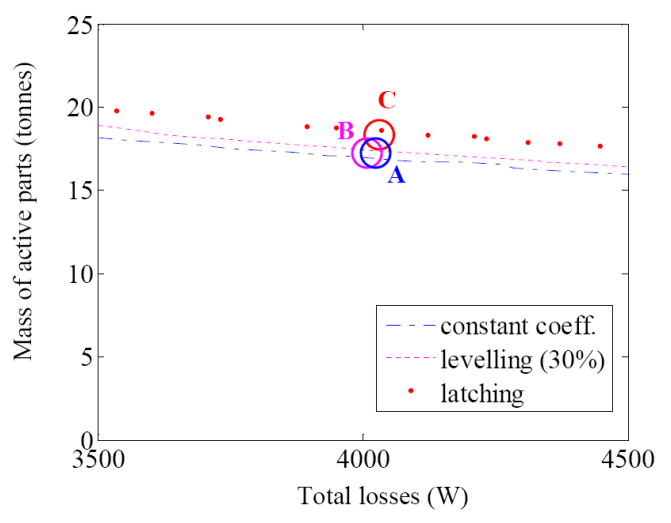

Fig. 23: Zoom of the Pareto front presented on figure 22

\begin{tabular}{lccc} 
& $\mathrm{A}(-.-)$ & $\mathrm{B}(-)$ & $\mathrm{C}()$. \\
\hline Total active mass (tonnes) & 17 & 17.4 & 18.6 \\
\hline Magnet mass (tonnes) & 7.4 & 7 & 7 \\
\hline Active volume (m3) & 2.0 & 2 & 2.2 \\
\hline External radius (m) & 4.3 & 4 & 4.4 \\
\hline Length $(\mathrm{m})$ & 0.5 & 0.5 & 0.5 \\
\hline Number of poles pair $(\mathrm{p})$ & 471 & 491 & 497 \\
\hline$<$ Pj+Pmg $>(\mathrm{kW})$ & 3.9 & 4 & 4.1 \\
\hline
\end{tabular}

TABLE V: Optimization resultats in direct drive

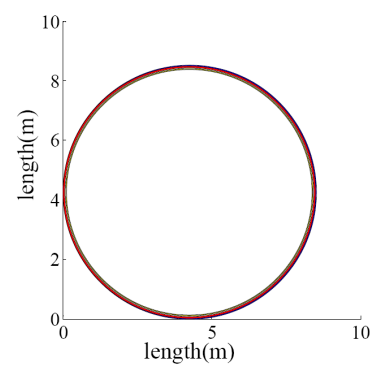

(a)

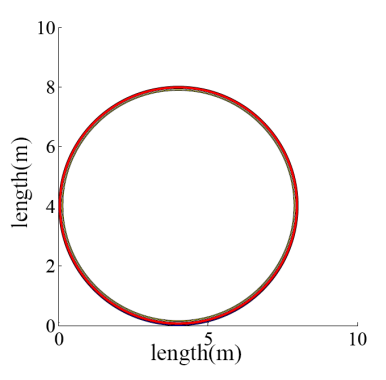

(b)
Fig. 24: Optimal geometry when employing the various control strategies ((a): constant $\beta$; b: power leveling)

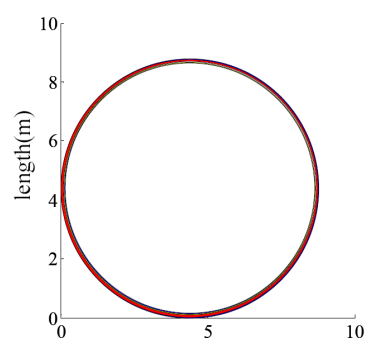

Fig. 25: Optimal geometry when employing the latching control

\section{Conclusion}

This article presented firstly the wave energy converter SEAREV. Secondly, a design methodology for the allelectric solution adapted to SEAREV was proposed. Three control modes were studied, specifically one with a constant viscous damping over the swell cycle with a given set of characteristics and power leveling. This particular mode strikes a better economic compromise in designing the entire power conversion chain. Moreover, this control method seems quite straightforward to implement under real world conditions, since sea state characteristics do not in reality change abruptly, and adjusting damping based on a direct evaluation of the sea state can be easily conceived. Optimization results on the peak power design (high levels for the power electronic converter) and in terms of electromagnetic generator mass, with a very large number of poles, were compared across the various control modes. The viscous damping and leveling control therefore appear to be the most promising, although considerable work still needs to be carried out. Power leveling actually requires a field-weakening operating range, and the autopilot angle parameter is to be included in the optimization approach. The incorporation of all system execution constraints will moreover make it possible to determine which electromagnetic conversion structures and electromechanical architecture work best for optimal lever integration. The design methodology described in this article can thus be reused with the specific design models of the selected structure. Two PTO technologies have been presented: hydroelectric and the all-electric. For now, it is difficult to compare the two solutions objectively without any real system optimization.

\section{REFERENCES}

[1] T. THORPE, Wave Energy, Chap. 15 of 2004 Survey of Energy Resources, World Energy Council, 2004, pp. 401-417.

[2] http://www.ifremer.fr/anglais/

[3] A. BABARIT, Hydrodynamic optimisation and optimal control of a wave energy converter, In French Optimisation hydrodynamique et contrêle optimal d'un récupérateur d'énergie des vagues, Thesis, 2005.

[4] A.H. CLEMENT and al., French patent, Autonomous electrical system for wave energy conversion, In French Système Electrique Autonome de Récupération de l'Energie des Vagues, 2004.

[5] B. MOLIN Hydrodynamic of offshore structures, in French Editions TECHNIP, Paris, 2002.

[6] J. FALNES, Ocean Waves and Oscillating Systems: linear interactions including wave-energy extraction, Cambridge University Press, 2002.

[7] C. JOSSET, A. BABARIT and A.H. CLEMENT, A Wave-toWire model of the SEAREV Wave Energy Converter, Journal of Engineering for the Maritime Environment, accepted for publication in Nov. '06.

[8] A. BABARIT, A.H. CLEMENT, Shape optimization of the SEAREV Wave Energy Converter, 9th World Renewable Energy Congress, Florence, 2006.

[9] M. RUELlAN, H. BEN AHMED, B. MULTON, A BABARIT and A.H. CLEMENT, Control influence on electromagnetic generator pre-design for wave energy converter. ICEM 2006, Chania, CD-ROM Proc., Sept. 2-5, 2006, 7 p.

[10] J. HALS, T. BJARTE-LARSSON, J. FALNES. Optimum reactive control and control by latching of a wave-absorbing semisubmerged heaving sphere. Proc. of OMAEŠ02, 21st International Conference on Offshore Mechanics and Arctic Engineering, pages 1Ü9, June 2002. 
[11] J. REGNIER, B. SARENI, X. ROBOAM and S. ASTIER, Optimal design of electrical engineering systems using Pareto Genetic Algorithms, 10th European Conference on Power Electronics and Applications, Toulouse, 2003.

[12] E. FITAN, F. MESSINE, B. NOGAREDE, The electromagnetic actuator design problem: a general and rational approach. IEEE Transactions on Magnetics, Volume 40, No. 3, May 2004.

[13] M.A. MUELLER, H. POLINDER, N. BAKER, Current and Novel Electrical Generator Technology for Marine Renewable Energy Applications. IEMDC 2007, Antalya, CD-ROM Proc., Mai, 2007, 6 p. 